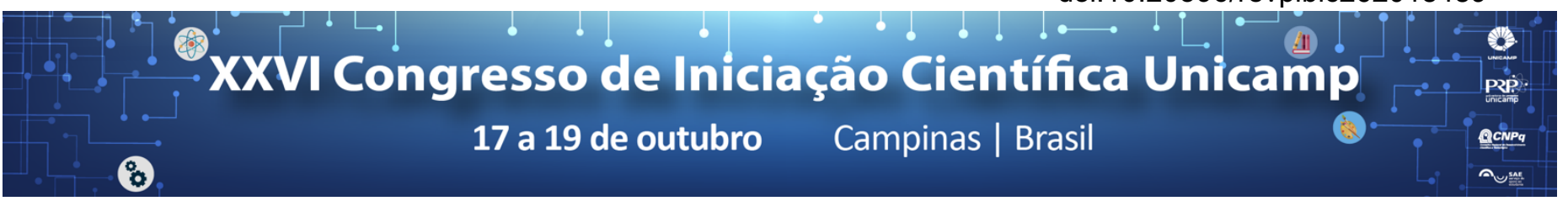

\title{
Effects of postharvest application of UV-C radiation on the control of microorganisms and maintenance of quality in strawberries
}

\author{
Gabriel P. Petrielli*, Raysa M. Alves, Franciane C. S. Usberti.
}

\begin{abstract}
Because it is a highly perishable fruit, due to its high metabolic activity and water content, the strawberry has a shelf life limited by weight loss, texture alteration and microbiological deterioration. Such susceptibility to proliferation of microorganisms and the occurrence of postharvest diseases, especially some rot, stimulates the study of alternative sanitizing treatments that aims at the maintenance of fruit quality such as ultraviolet radiation, which it exhibits germicidal properties in the region UV-C (200-280nm). The non-formation of residual toxic compounds on the surface of the product, a low cost and the fact of being odorless are advantages of its use in fruits and vegetables. ${ }^{1}$ In the present study the objective was to evaluate the efficacy and effects of UV-C radiation in strawberries by applying 0.0 (T1), 1.25 (T2), 2.50 (T3), 3.75 (T4) and 5.0 (T5) kJ/m² and storage at $5.37 \pm 0.74{ }^{\circ} \mathrm{C}$ and $53.38 \pm 6.84 \% \mathrm{RH}$ after irradiation. The experiment was conducted in a completely randomized blocks design with three replicates per treatment. In the results, it was not possible to observe some benefits of UV-C in strawberries in relation to their non-use, suggesting it needs further studies with different doses and storage conditions.
\end{abstract}

\section{Key words:}

Fragaria ananassa, microbial control, sanitation.

\section{Introduction}

The application of ultraviolet (UV-C) radiation in foods is based on the germicidal properties of UV light in the wavelength between 200 and $280 \mathrm{~nm}$. Due to the beneficial impacts of this method on the microbiological control, its use in highly perishable products, such as strawberry, arouses the interest of study; however, it is worth emphasizing that the effects of this treatment are correlated with radiation dose and storage conditions.

The objective of this work was to evaluate the hypothesis that the application of UV-C radiation is effective in inhibiting microbiological growth and maintaining the postharvest quality of strawberries.

\section{Results and Discussion}

It was observed visually that the T4 treatment was the least effective among the others, as well as the color analysis showed that the strawberries submitted to the T4 treatment had the lowest tonal values, with a mean of 33.12 and 32.29 at 2 and 5 days, respectively.
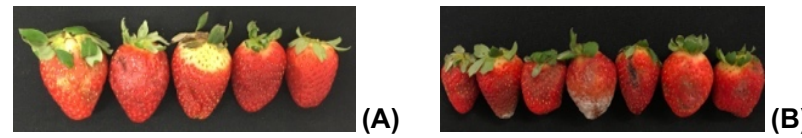

Image 1. Fruits treated with T4 at $2(\mathrm{~A})$ and $5(\mathrm{~B})$ days.

The microbiological analysis showed that the treatments with the highest radiation dose did not have beneficial effects in the control of molds and yeasts, contrary to the results obtained by CAVASINI et al. in an experiment carried out in the same laboratory. In addition, among the treatments used, the only treatment that was not statistically maleficent to strawberries, when compared to the control, was T3 treatment. After 5 days, a high incidence of microbiological contamination, loss of mass and negative visual appearance was observed, which would not please consumer preference and made the evaluations unviable at 7 days of storage.
Chart 1. Microbiological analysis for treatments in colony forming units. * $p<0.05$ were considered significant.

\begin{tabular}{ccc}
\hline Treatment & 2 Days & 5 Days \\
\hline $0.00 \mathrm{~kJ} / \mathrm{m}^{2}$ & $7.0 \times 10^{3}$ & $3.8 \times 10^{4}$ \\
$1.25 \mathrm{~kJ} / \mathrm{m}^{2}$ & $2.4 \times 10^{4}$ & $5.5 \times 10^{4}$ \\
$2.50 \mathrm{~kJ} / \mathrm{m}^{2}$ & $2.1 \times 10^{4}$ & $8.0 \times 10^{4}$ \\
$3.75 \mathrm{~kJ} / \mathrm{m}^{2}$ & $2.1 \times 10^{4}$ & $1.1 \times 10^{5^{*}}$ \\
$5.00 \mathrm{~kJ} / \mathrm{m}^{2}$ & $2.0 \times 10^{4}$ & $3.5 \times 10^{5^{*}}$
\end{tabular}

The other quality parameters evaluated, such as acidity, soluble solids content, $\mathrm{pH}$, respiration and mass loss did not present statistically significant differences between treatments and control. Despite this, it is emphasized that respiration and mass loss were higher for the higher dosage treatments.
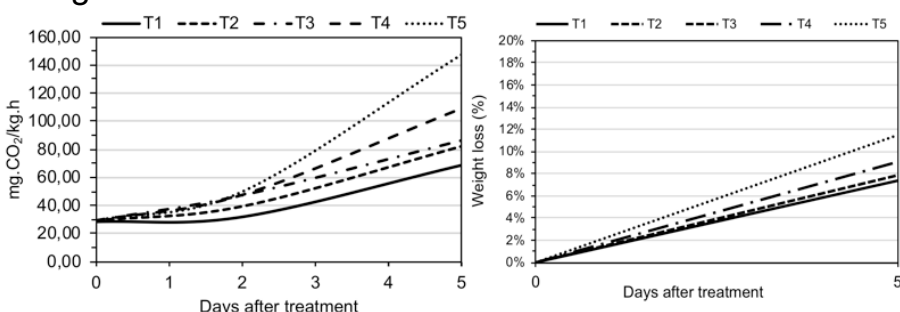

Image 2. Respiratory rate $(A)$ and weight loss $(B)$ of the strawberries treated with 0.0 (T1), 1.25 (T2), 2.50 (T3), 3.75 (T4) and 5.0 (T5) kJ / m².

\section{Conclusions}

It's concluded that the treatments with ultraviolet radiation did not present benefits regarding the non-use of the radiation for the quality parameters evaluated in this experiment.

\section{Acknowledgement}

CNPQ, for financial support

\footnotetext{
KEYSER, M; MULLER, I. A.; CILLIERS, F. P.; NEL, W ; GOUWS, P. A Ultraviolet radiation as a non-thermal treatment for the inactivation of microorganisms in fruit juice. Innovative Food Science and Emerging Technologies, v. 9, p. 348-354, 2008.

${ }^{2}$ CAVASINI, R.; USBERTI, F. C. S.; FERRAZ, A. C. de. O. Conservação póscolheita de morangos após radiação ultravioleta. Anais... Congresso Brasileiro de Engenharia Agrícola - CONBEA, 45., Florianópolis - SC. 2016.
} 